\title{
EDITORIAL
}

\section{CHALLENGE OF 21ST CENTURY TO INTEGRATE THE REPRODUCTIVE TECHNOLOGIES CONCERNING THE BEGINNING OF HUMAN LIFE}

Religion is significantly important to understand how the 21 st century will integrate the new reproductive technologies concerning the beginning of human life. As religious interpretation of "creation" has a strong impact on society, therefore, the influence of religion may limit the proper ethical incorporation of reproductive technologies.

As for example, according to Hinduism the "self" (atman) is part of the creative force (Brahman) and life energy residing in all creation. A person cannot "play God", because in an ultimate sense of the "self" is God. Hindu thinks human animating spirit is present from the fertilization. So the embryo is given the status of personhood throughout the pregnancy. Therefore, Hindu thought is concerned with moral attitudes toward research on the pre-embryo is exploitation of the vulnerable.

On the other hand, Islamic Code of Medical Ethics gives the moral status of the human embryo from the current fixations of heart beat (14th day after fertilization). Majority scholars say embryo as human at the end of the fourth month or around 120 days when self movement of embryo is established. It is an important consideration in discussions regarding termination of pregnancy, chorionic villous biopsy (in first trimester) and prenatal screening. Further, all Muslim authorities agree that termination of pregnancy is justified if the continuation of pregnancy places a mother's life in danger. Termination for any other reason is strongly and consistently discouraged, particularly after ensoulment. However, it seems that the use of third party reproduction in Islam is problematic. According to Islamic Jurisprudence (Shari'a Law) procreative and parenting relationships are lawful between valid spouses because of designated role-responsibilities, legitimacy, lineage, possible incest and inheritance.

Roman Catholic bans all types of reproductive technologies. Even if among Catholic believers there is a wide variety of attitude and ideas about it, showing a complex reality more or less close to the Vatican's teachings. In school of Protestant accept the expansion of human freedoms but control over human reproduction (Joseph Fletcher). Paul Ramsey thinks risk for compromising humanity and basic concepts of human procreation. The Anglican Church is less rigid in its views and has not condemned the practice of surrogacy.

Different religions have different notions regarding the beginning of life. It may limit the access of benefits of the technology. So it is crucially important for the researchers to incorporate religion in such a way that all the people of globe can get benefit from the new reproductive technology.

Shamima Parvin Lasker

Professor and Head of Anatomy, City Dental College, Bangladesh

Associate Editor

Bangladesh Journal of Bioethics 